\title{
Telomeres in Neonates: New Insights in Fetal Hematopoiesis
}

\author{
ULRIKE FRIEDRICH, MATTHIAS SCHWAB, ERNST-ULRICH GRIESE, PETER FRITZ, AND \\ ULRICH KLOTZ \\ Dr. Margarete Fischer-Bosch Institute of Clinical Pharmacology and Robert Bosch Hospital, Department \\ of Pathology, Robert Bosch Hospital, 70376 Stuttgart, Germany
}

\section{ABSTRACT}

\begin{abstract}
Progressive telomere shortening occurs in somatic cells, and with increasing donor age a significant decline in telomere length has been shown in various postnatal tissues. In contrast, little is known about changes in telomere length during human fetal development. Therefore, we measured telomere length in the leukocyte fraction of umbilical cord blood samples from 15 preterm ( $<37 \mathrm{wk}$ of gestation) and 11 full-term ( $>37 \mathrm{wk}$ of gestation) neonates using the telomere restriction fragment assay. Whereas no differences in mean $( \pm \mathrm{SD})$ telomere restriction fragment between the groups of preterm neonates $(8512 \pm 523$ bp) and full-term newborns $(8323 \pm 503 \mathrm{bp})$ could be found, significantly longer telomeres $(p=0.002)$ were found in very low birth weight preterm neonates when compared with low birth weight preterm neonates. In addition, a rapid and significant decline in mean telomere restriction fragment was observed
\end{abstract}

between 27 and 32 wk of gestation ( $p=0.02, r=0.79$ ) followed by a period of no significant loss of telomere repeats between 33 and 42 wk of gestation. These results are consistent with the known almost maximal proliferation rate of hematopoietic progenitor cells before $32 \mathrm{wk}$ of gestation. The initial decrease in telomere restriction fragment could be caused by ontogenyrelated functional alterations of hematopoietic cells or differences in stem cell turnover or the rate of telomere loss per cell division. (Pediatr Res 49: 252-256, 2001)
TRF, telomere restriction fragment
VLBW, very low birth weight
LBW, low birth weight

Telomeres play a major role in chromosome structure and function by protecting their degradation and apparently contributing to the attachment of chromosome ends to the nuclear envelope. Telomeres lose a portion of their noncoding repetitive DNA sequences with each cell division, and the ribonucleoprotein enzyme telomerase can compensate for this by synthesis of telomere repeats onto chromosomes (1-3). Despite the observation that some immortalized cell lines manifest stable telomeres without evidence of telomerase activity (4), telomerase-dependent telomere elongation seems to be the most important mechanism for maintaining telomere length in vitro and in vivo.

In man telomerase is expressed during embryogenesis. Ulaner and Giudice (5) examined telomerase activity in various fetal tissues from 8 to $21 \mathrm{wk}$ of gestation. They found that all tissues expressed telomerase at the earliest ages analyzed, followed by tissue-specific suppression during embryogenic development. After birth this enzyme is repressed in most

Received May 25, 2000; accepted August 25, 2000.

Correspondence: U. Klotz, Ph.D., Dr. Margarete Fischer-Bosch-Institut für Klinische Pharmakologie, Auerbachstrasse 112, D-70376 Stuttgart, Germany.

Supported by the Robert Bosch Foundation, Stuttgart, Germany. somatic tissues (6), and high activity persists only in germline cells.

Whereas in most postnatal somatic tissues telomerase is not expressed, low levels of this enzyme are detected in hematopoietic progenitor cells, activated lymphocytes (7), intestinal crypt cells (8), the basal layer of the skin (9), and during the proliferative phase in the premenopausal endometrium (10, 11). It is assumed that the low telomerase activity compensates the increased loss of telomere repeats associated with the high rate of cell turnover in these tissues. However, in contrast to germline and tumor cells, these low levels are insufficient to maintain telomere length. A rate of telomere loss of about 40 $\mathrm{bp} / \mathrm{y}$ in lymphocytes (12), $15 \mathrm{bp} / \mathrm{y}$ in fibroblasts (13), and even $9 \mathrm{bp} / \mathrm{y}$ in hematopoietic progenitor cells (14) has been noted. Recently, different studies have shown that rates of telomere attrition in blood cells are highly variable at different ages, with a surprisingly rapid telomere loss in young children (15-17).

Some studies have been conducted to analyze telomere length in cord blood samples of full-term neonates $(14,15,18)$. However, little is known about variations in telomere length during fetal development. It has been shown that genetic factors play an important role in telomere length (19). This might be the most important factor for the substantial variation 
of up to $2 \mathrm{~kb}$ that has been observed among individuals of the same age. It remains to be elucidated whether the wide scatter in telomere length could reflect interindividual telomere length differences in the germ line, in turnover rate, or by different numbers of base pairs lost during each cell division. Analysis of telomeres in umbilical cord blood of preterm and full-term neonates could help to answer the question of whether gestational age is an important variable that has an influence on telomere length.

In the fetus, hematopoietic stem cells originate from the yolk sac. Later on, spleen and, predominantly, fetal liver are organs of hematopoiesis before the bone marrow starts to play a leading role (20). Umbilical cord blood contains many hematopoietic progenitor cells (21-23). In agreement with the higher ex vivo proliferative potential of purified progenitor cells from cord blood compared with adult bone marrow (24), significantly longer telomeres have been observed in umbilical cord blood (14).

In summary, telomere length has been shown to be a biomarker of the replicative history and predicts future replicative capacity (13). Moreover, ontogeny-related changes in proliferative potential of hematopoietic cells are known (24), and restrictions of proliferative capacity have been associated with the development of neutropenia in neonates (25). Therefore, we addressed our study to the relationship between gestational age and telomere length to provide some new insights into developmental hematopoiesis.

\section{METHODS}

Patient samples. Umbilical cord blood samples were collected from the placental end of the cord after delivery of 11 full-term $(>37 \mathrm{wk}$ of gestational age) and 15 preterm $(<37$ wk) neonates including six VLBW $(<1500 \mathrm{~g})$ and seven LBW $(1500-2500 \mathrm{~g})$ newborns. Within the group of the seven male and eight female preterm neonates, the causes for prematurity in nine cases were premature labor onset (owing to multiple pregnancy in two cases), rupture of membranes in three cases, and amnionitis and premature abruptio placenta in one case each. The Apgar score of all preterm neonates after $1 \mathrm{~min}$ ranged from 5 to 9 and improved up to values between 8 and 10 after $10 \mathrm{~min}$. EDTA-treated blood samples were stored at $4^{\circ} \mathrm{C}$ until extraction of DNA. The study was approved by the local ethics committee, and informed consent was obtained from the mothers.

DNA extraction. Genomic DNA was prepared from leukocytes isolated from whole blood samples (26). The concentration of DNA was quantified by UV absorption measurement at $260 \mathrm{~nm}$. For TRF analysis the DNA was digested with $2 \mathrm{U} / \mu \mathrm{g}$ DNA HinfI (New England Biolabs, Schwalbach, Germany) overnight at $37^{\circ} \mathrm{C}$. Integrity of the DNA and successful digestion was monitored before and after restriction by agarose gel electrophoresis.

Analysis of telomere length (TRF assay). Five micrograms of HinfI-digested DNA was loaded onto $0.8 \%$ agarose gels and separated by electrophoresis at $60 \mathrm{~V}(3 \mathrm{~V} / \mathrm{cm})$ for 15 to $16 \mathrm{~h}$. The 1-kb DNA ladder (GIBCO BRL, Karlsruhe, Germany) served as a molecular weight marker. After UV exposure $(\lambda=$
$302 \mathrm{~nm}$ ) for $5 \mathrm{~min}$ the gels were denatured and vacuum blotted to a positively charged nylon membrane (Boehringer Mannheim, Mannheim, Germany) according to the manufacturer's protocol. After cross-linking the DNA to the membrane with UV light, the filters were hybridized to a digoxigenin-labeled (TTAGGG) 7 telomeric probe (Roth, Karlsruhe, Germany). Hybridization was performed overnight at $42^{\circ} \mathrm{C}$. Blots were washed twice for $15 \mathrm{~min}$ in $2 \times \mathrm{SSC} / 0.1 \% \mathrm{SDS}$ at $42^{\circ} \mathrm{C}$, once for $5 \mathrm{~min}$ in $2 \times \mathrm{SSC}$ (standard saline-citrate) at room temperature, and afterward for $5 \mathrm{~min}$ in $1 \times$ maleic acid $/ 0.1 \%$ Tween. Detection of the DNA fragments that had hybridized to the digoxigenin-labeled probes was performed by chemiluminescence following the manufacturer's instructions (Boehringer Mannheim). Filters were exposed within the linear range of the chemiluminescence reaction for 1-5 min. Films (Hyperfilm, Amersham Buchler, Braunschweig, Germany) were scanned and analyzed using the One-Dscan 1.0 (Scananalysis, Billerica, Ontario, Canada) and Quattro Pro 6.0 Software (Corel Corporation, Ottawa, Ontario, Canada). Average fragment length per lane was calculated as weighted mean of the OD using the formula $L=\Sigma\left(\mathrm{OD}_{\mathrm{i}} \cdot L_{\mathrm{i}}\right) / \Sigma \mathrm{OD}_{\mathrm{i}}$, where $\mathrm{OD}_{\mathrm{i}}$ is the integrated signal in interval $i$ and $L_{\mathrm{i}}$ is the TRF length at the midpoint of interval $i$. Each DNA sample was analyzed on three or four different gels.

Statistical analysis. Statistical tests were performed using the GraphPad Prism 2.0 software (GraphPad Software Inc., San Diego, CA, U.S.A.). Groups were compared using the Mann-Whitney test. Values of $p<0.05$ were considered statistically significant. The relationship between TRF length and gestational age was estimated by linear regression.

\section{RESULTS}

Determination of telomere length. Telomere length was analyzed by the TRF assay as described. A representative blot is shown in Figure 1. The hybridization patterns, visible as a smear, indicated considerable interchromosomal variation in TRF length as well as intercellular variation in replicative history. To assess the reproducibility of the TRF analysis, each cord blood sample was analyzed on at least two TRF Southern blots, revealing an averaged interassay variability of $6.1 \%(514$ bp).

Telomere length in preterm versus full-term neonates. Data for mean TRF length in cord blood samples of 15 preterm ( $<37 \mathrm{wk}$ of gestation) and 11 full-term $(>37 \mathrm{wk}$ of gestation) neonates are shown in Table 1. Although there might be a trend to shorter telomeres $(p=0.06)$ with increasing gestational age, no significant relationship was found between TRF and gestational age (Fig. 2, Top). Because premature neonates represent considerable differences in maturity, we discriminated further between $<32$ and $>32$ gestational wk. A significant decline ( $p=0.02, r=0.79$ ) of telomere length was found with increasing gestational age between 27 and 32 wk of gestation (Fig. 2, Bottom). In addition, stratification of neonates by birth weight was chosen as a further clinically used factor. Telomere length was found to be significantly longer $(p=0.002)$ in VLBW preterm neonates when compared with LBW neonates (Fig. 3). 


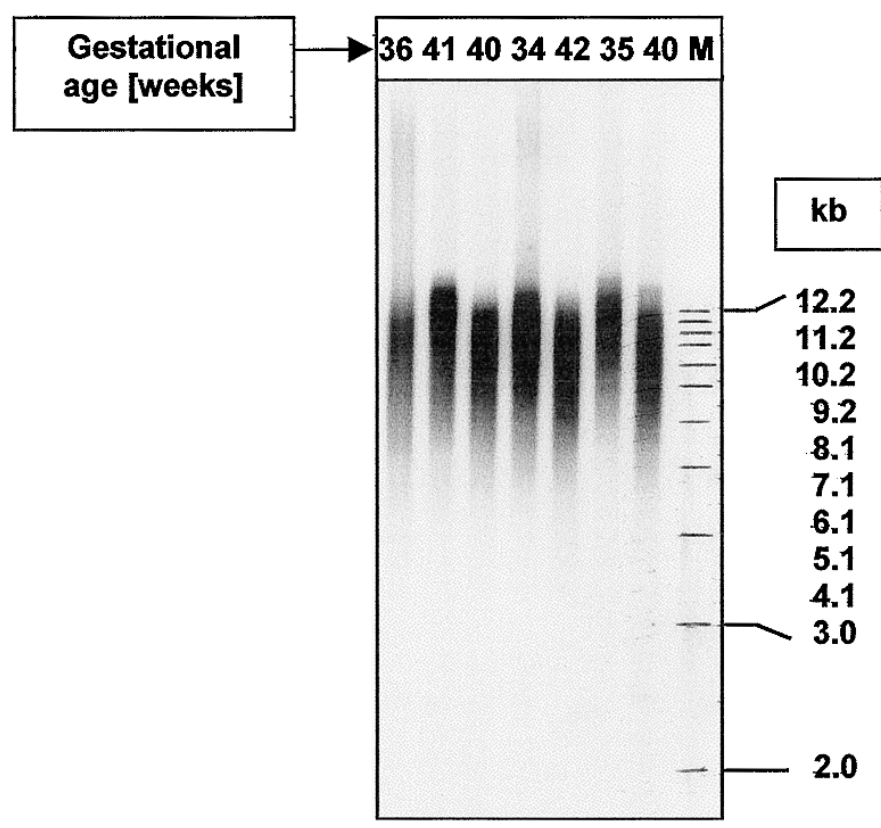

Fig. 1. A representative Southern blot with cord blood samples of seven newborns is shown. Weeks of gestation at the time of birth are indicated at the top of the figure. $M$ represents the marker lane (1-kb ladder) with the sizes of the marker bands indicated at the right margin.

Table 1. Telomere length in umbilical cord blood samples of preterm and full-term newborns

\begin{tabular}{lcc}
\hline \multicolumn{1}{c}{ Variable } & $\begin{array}{c}\text { Preterm newborns } \\
(<37 \text { wk of gestation })\end{array}$ & $\begin{array}{c}\text { Full-term newborns } \\
(>37 \text { wk of gestation })\end{array}$ \\
\hline$n$ & 15 & 11 \\
Minimum (bp) & 7491 & 7535 \\
Maximum (bp) & 9473 & 8955 \\
Median (bp) & 8554 & 8244 \\
Mean (bp) & 8512 & 8323 \\
SD (bp) & 523 & 503 \\
CV (\%) & 6.1 & 6.0 \\
$95 \%$ CI (bp) & $8223-8802$ & $7985-8661$ \\
\hline
\end{tabular}

$\mathrm{CV}$, coefficient of variation; $\mathrm{CI}$, confidence interval.

\section{DISCUSSION}

More detailed information about telomere loss during fetal development is of great interest inasmuch as telomere length has been found to correlate with cell turnover and further replicative potential, and both aspects play an important role during fetal development. Therefore, we have applied the conventional TRF assay to analyze telomere length in the leukocytes of cord blood samples from preterm and full-term neonates. Although telomere length might differ slightly between subpopulations of leukocytes during fetal development, generally the composition of the leukocyte fraction is comparable in preterm and full-term neonates (27).

The TRF length in the 11 full-term newborns covered a range between $7535 \mathrm{bp}$ and $8955 \mathrm{bp}$, which has also been shown in previous studies $(14,16,18)$. Whereas no differences were found in TRF between the 15 preterm and 11 full-term neonates using $37 \mathrm{wk}$ of gestation as the cutoff according to the World Health Organization definition, we observed significantly shorter telomeres in LBW (1500-2500 g) preterm neonates in contrast to VLBW $(<1500 \mathrm{~g})$ preterm neonates. a

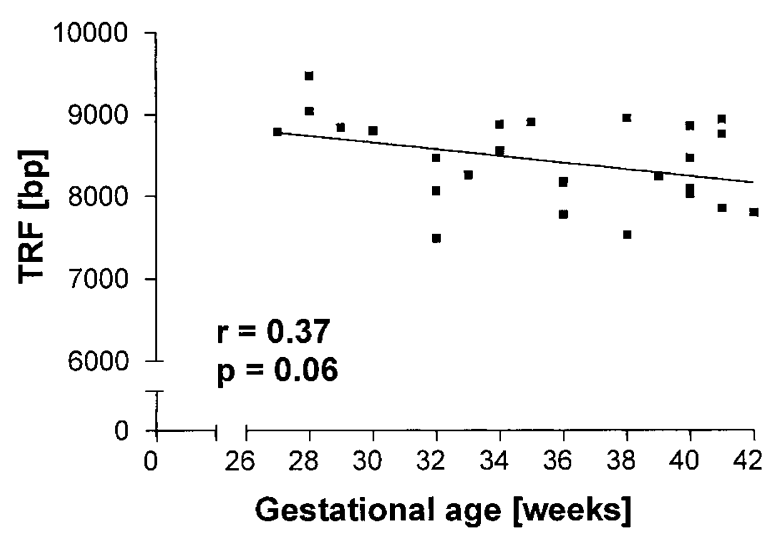

b

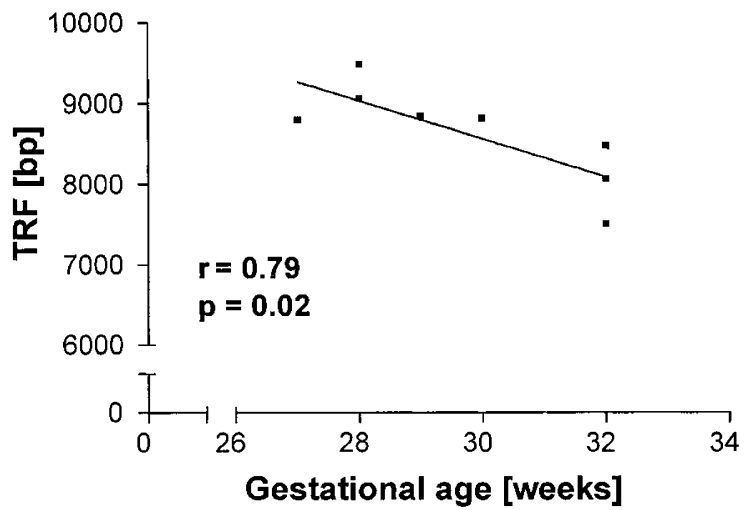

Fig. 2. Mean TRF length as a function of gestational age; each point represents the mean of at least two separate TRF analyses. Top, data of all analyzed samples (slope, $-41 \pm 21 \mathrm{bp}$ ). Bottom, relationship between mean TRF length and gestational age in preterm neonates (27 to $32 \mathrm{wk}$ of gestation); the slope of the linear regression line is significantly different ( $p=0.02$; slope, $-238 \pm$ $71 \mathrm{bp})$.

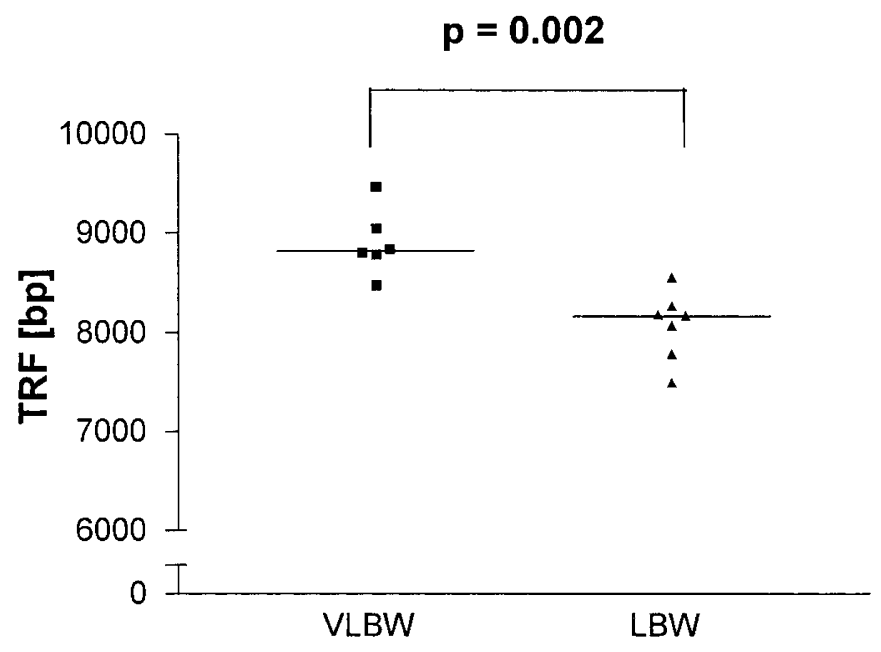

Fig. 3. Comparison of telomere length in cord blood between VLBW and LBW preterm neonates. The means from at least two separate TRF analyses of all individuals and the medians for both groups are given. Comparisons between the groups were performed with the Mann-Whitney test $(p=0.002)$.

Comparing birth weight with gestational age, 32 wk of gestation represents the cutoff for distinguishing between VLBW and LBW preterm neonates. This stratification is confirmed by the well-established clinical observation that preterm neonates 
before 32 wk of gestation have a distinctly higher risk of complication, resulting in severe morbidity and mortality (28).

The most striking aspect of our study is the rapid and significant decline of telomere attrition in the preterm neonates between 27 and 32 wk of gestation. In contrast, the period beyond 32 wk of gestation is characterized by a wide interindividual variability of TRF, which has been additionally observed in various age groups (e.g. full-term neonates, children, elderly) and is related to the strong genetic influence on telomere length regulation $(17,19)$.

Two explanations for this gestational age-dependent biphasic profile of mean TRF should be considered: 1) ontogenyrelated functional alterations of hematopoietic cells, and 2) differences in stem cell turnover or rate of telomere loss per cell division.

Ontogeny-related qualitative differences in the ability to generate $\mathrm{CD}_{3}{ }^{+}$daughter cells have been found among cultures originating from purified cells from cord blood, fetal liver, and adult bone marrow (24). Additionally, Christensen et al. (29) observed a specific pattern of granulocyte-macrophage progenitor cell (granulocyte-macrophage colony-forming unit(s)) differentiation in premature neonates (28 to $32 \mathrm{wk}$ of gestation) compared with full-term neonates who showed no differences from adults. Interestingly, we also found the most striking changes in telomere loss in this phase of gestational age. In this context, it remains to be determined whether telomerase is altered during maturation of hematopoietic cells in fetal development because this enzyme has been shown to be highly regulated during the development and activation of both $\mathrm{T}$ and B lymphocytes (30).

Despite telomerase activity, progressive telomere shortening was observed in leukocytes as well as in hematopoietic progenitors during aging in vivo and in vitro $(14,18)$. Recently, it was shown that telomeric sequences are not lost at a constant rate throughout life, and the most rapid telomere loss (up to 20 bp weekly) has been observed in children up to the age of $4 \mathrm{y}$ (15-17). Interestingly, between 27 and 32 wk of gestation the rate of telomere attrition (240 bp per week) even exceeded those in young children, assuming an increased proliferation rate during this period of gestation.

Several investigations support this hypothesis. Christensen et al. (29) have shown that the proliferating rate of circulating committed granulocyte-macrophage colony-forming unit(s) is significantly higher in neonates compared with adults, with the highest maximal or near maximal proliferating rates measured in premature neonates delivered before $32 \mathrm{wk}$ of gestation. More recently, Lansdorp et al. (24) found that the total number of $\mathrm{CD}_{3} 4^{+}$cells in cultures that were derived from bone marrow cells of adults remained constant, whereas an increasing number of $\mathrm{CD}_{3} 4^{+}$cells were observed in cell cultures originating from purified cord blood, and even more with purified fetal liver. Therefore, the large drop observed in telomere length between 27 and 32 wk of gestation most likely reflects the very high proliferation rate of hematopoietic progenitor cells. Moreover, prenatal infections could accelerate cell turnover in hematopoietic cells and might therefore contribute to an increased loss of telomeres. To our knowledge, this has not been investigated intensively in previous studies.
In summary, our investigations provide a first insight on telomere dynamics during gestational age and could be useful for a better understanding of human ontogenesis as well as fetal hematopoiesis. However, more extended studies are necessary to clarify the mechanisms of telomere length regulation during this time.

Acknowledgments. The authors thank Prof. Wolfgang Simon (Robert Bosch Hospital, Stuttgart), Prof. Axel Feige (Women's Hospital II, Nürnberg-Süd), and Dr. Andrea Henke (Women's Hospital Berg, Stuttgart), as well as the nursing staff, for providing us with umbilical cord blood samples, Dr. Thomas von Zglinicki and Dr. Tim H. Brümmendorf for helpful discussion, and Dr. Nadja Gugeler for statistical analysis.

\section{REFERENCES}

1. Blackburn EH 1991 Structure and function of telomeres. Nature 350:569-573

2. Greider CW, Blackburn EH 1985 Identification of a specific telomere terminal transferase activity in Tetrahymena extracts. Cell 43:405-413

3. Greider CW, Blackburn EH 1989 A telomeric sequence in the RNA of Tetrahymena telomerase required for telomere repeat synthesis. Nature 337:331-337

4. Bryan TM, Englezou A, Dalla-Pozza L, Dunham MA, Reddel RR 1997 Evidence for an alternative mechanism for maintaining telomere length in human tumors and tumor-derived cell lines. Nat Med 3:1271-1274

5. Ulaner GA, Giudice LC 1997 Developmental regulation of telomerase activity in human fetal tissues during gestation. Mol Hum Reprod 3:769-773

6. Wright WE, Piatyszek MA, Rainey WE, Byrd W, Shay JW 1996 Telomerase activity in human germline and embryonic tissues and cells. Dev Genet 18:173-179

7. Hiyama K, Hirai Y, Kyoizumi S, Akiyama M, Hiyama E, Piatyszek MA, Shay JW, Ishioka S, Yamakido M 1995 Activation of telomerase in human lymphocytes and hematopoietic progenitor cells. J Immunol 155:3711-3715

8. Hiyama E, Hiyama K, Tatsumoto N, Kodama T, Shay JW, Yokoyama T 1996 Telomerase activity in human intestine. Int J Oncol 9:453-458

9. Härle-Bachor C, Boukamp P 1996 Telomerase activity in the regenerative basal layer of the epidermis in human skin and immortal and carcinoma-derived skin keratinocytes. Proc Natl Acad Sci USA 93:6476-6481

10. Brien TP, Kallakury BVS, Lowry CV, Ambros RA, Muraca PJ, Malfetano JH, Ross JS 1997 Telomerase activity in benign endometrium and endometrial carcinoma. Cancer Res 57:2760-2764

11. Tanaka M, Kyo S, Takakura M, Kanaya T, Sagawa T, Yamashita K, Okada Y, Hiyama E, Inoue M 1998 Expression of telomerase activity in human endometrium is localized to epithelial glandular cells and regulated in a menstrual phase-dependent manner correlated with cell proliferation. Am J Pathol 153:1985-1991

12. Vaziri H, Schächter F, Uchida I, Wei L, Zhu X, Effros R, Cohen D, Harley CB 1993 Loss of telomeric DNA during aging of normal and trisomy 21 human lymphocytes. Am J Hum Genet 52:661-667

13. Allsopp RC, Vaziri H, Patterson C, Goldstein S, Younglai EV, Futcher AB, Greider CW, Harley CB 1992 Telomere length predicts replicative capacity of human fibroblasts. Proc Natl Acad Sci USA 89:10114-10118

14. Vaziri H, Dragowska W, Allsopp RC, Thomas TE, Harley CB, Lansdorp PM 1994 Evidence for a mitotic clock in human hematopoietic stem cells: loss of telomeric DNA with age. Proc Natl Acad Sci USA 91:9857-9857

15. Frenck RW, Blackburn EH, Shannon KM 1998 The rate of telomere sequence loss in human leukocytes varies with age. Proc Natl Acad Sci USA 95:5607-5610

16. Zeichner SL, Palumbo P, Feng YR, Xiao X, Gee D, Sleasman J, Goodenow M, Biggar R, Dimitrov D 1999 Rapid telomere shortening in children. Blood 93:28242830

17. Rufer N, Brümmendorf TH, Kolvraa S, Bischoff C, Christensen K, Wadsworth L, Schulzer M, Lansdorp PM 1999 Telomere fluorescence measurements in granulocytes and $\mathrm{T}$ lymphocyte subsets point to a high turnover of hematopoietic stem cells and memory T cells in early childhood. J Exp Med 190:157-167

18. Engelhardt M, Kumar R, Albanell J, Pettengell R, Han W, Moore MAS 1997 Telomerase regulation, cell cycle, and telomere stability in primitive hematopoietic cells. Blood 90:182-193

19. Slagboom PE, Droog S, Boomsma DI 1994 Genetic determination of telomere size in humans: a twin study of three age groups. Am J Hum Genet 55:876-882

20. Tavassoli M 1991 Embryonic and fetal hematopoiesis: an overview. Blood Cells $1: 269-281$

21. Broxmeyer HE, Hangoc G, Cooper S, Ribeiro RC, Graves V, Yoder M, Wagner J, Vadhan-Raj S, Benninger L, Rubinstein P, Broun ER 1992 Growth characteristics and expansion of human umbilical cord blood and estimation of its potential for transplantation in adults. Proc Natl Acad Sci USA 89:4109-4113 
22. Almici C, Carlo-Stella C, Wagner JE, Mangoni L, Garau D, Rizzoli V 1997 Biologic and phenotypic analysis of early hematopoietic progenitor cells in umbilical cord blood. Leukemia 11:2143-2149

23. Wyrsch A, dalle Carbonare V, Jansen W, Chklovskaia E, Nissen C, Surbek D, Holzgreve W, Tichelli A, Wodnar-Filipowicz A 1999 Umbilical cord blood from preterm human fetuses is rich in committed and primitive hematopoietic progenitors with high proliferative and self-renewal capacity. Exp Hematol 27:1338-1345

24. Lansdorp PM, Dragowska W, Mayani H 1993 Ontogeny-related changes in proliferative potential of human hematopoietic cells. J Exp Med 178:787-791

25. Al-Mulla ZS, Christensen RD 1995 Neutropenia in the neonate. Clin Perinatol 22:711-739
26. Miller SA, Dykes DD, Polesky HF 1988 A simple salting out procedure for extracting DNA from human nucleated cell. Nucleic Acids Res 16:1215

27. Cloherty JP, Stark AR 1991 Manual of Neonatal Care. Little, Brown, Boston, pp 727-728

28. Behrmann RE, Vaughan VC, Nelson WE 1987 Nelson Textbook of Pediatrics. WB Saunders Company, Philadelphia, pp 373-374

29. Christensen RD, Harper TE, Rothstein G 1986 Granulocyte-macrophage progenitor cells in term and preterm neonates. J Pediatr 109:1047-1051

30. Weng NP, Hathcock KS, Hodes RJ 1998 Regulation of telomere length and telomerase in T and B cells: a mechanism for maintaining replicative potential. Immunity 9:151-157 